\title{
Constructivist Teaching/Learning Theory and Participatory Teaching Methods
}

\author{
Sithara YJN Fernando ${ }^{1}$ \& Faiz MMT Marikar ${ }^{1, *}$ \\ ${ }^{1}$ General Sir John Kothelawala Defence University, Ratmalana, Sri Lanka \\ *Correspondence: General Sir John Kothelawala Defence University, Ratmalana, Sri Lanka. E-mail: \\ faiz.marikar@fulbrightmail.org, sitharaf@gmail.com
}

Received: February 12, 2017

Accepted: March 1, 2017 Online Published: April 27, 2017

doi:10.5430/jct.v6n1p110

URL: https://doi.org/10.5430/jct.v6n1p110

\begin{abstract}
Evidence for the teaching involves transmission of knowledge, superiority of guided transmission is explained in the context of our knowledge, but it is also much more that. In this study we have examined General Sir John Kotelawala Defence University's cadet and civilian students' response to constructivist learning theory and participatory teaching methods, especially concepts and knowledge on the learning platform in the Defence University. Target population of this study represents 41 students. All students were given a questionnaire related to constructivist learning theory and participatory teaching methods. The claims of constructivist teaching/learning theory that this paper has singled out are the following: 1) learning is an active experience; 2) the ideas students hold about the subject and topic being taught will form a part of their learning experience; and 3) learning is socially and culturally rooted. Recent developments in Constructivist Teaching/Learning Theory was explained and briefly described in this paper.
\end{abstract}

Keyword: constructive learning; teaching; cadet

\section{Introduction}

Teaching involves transmission of knowledge, but it is also much more than that. Theories of teaching have to be sensitive to the processes through which students acquire knowledge, or in other words how students learn. It is in this aspect related to the processes through which students acquire knowledge that constructivist teaching and learning theory have much to offer. Constructivist teaching and learning theory advocates a participatory approach in which students actively participate in the learning process. For Ernest von Glaserfeld constructivism as a theory of knowledge puts forward the following two principles: "knowledge is not passively received but actively built up by the cognizing subject; and the function of cognition is adaptive and serves the organization of the experiential world, not the discovery of ontological reality"(VonGlaserfeld 1989). The core of the constructivist approach to teaching and learning as expounded by von Glaserfeld is that the student or the learner is an active participant in the learning process and that the teacher has to take account of that in the teacher's effort to facilitate learning. He also makes an effort to link the theory of constructivism to the practice of teaching (VonGlaserfeld 1989).

Svein Sjoberg identifies the core ideas of the constructivist approach to learning as knowledge is actively constructed by the learner, not passively received from the outside (Sjoberg 2007). Learning is something done by the learner, not something that is imposed on the learner as the key factor. According to Jia Shen "Participatory Learning Approach (PLA) incorporates several opportunities for learning...in designing problems, answering them, grading them, disputing results, and in observing/reading what everyone else does" (Shen, Wu et al. 2004). PLA can help a student to view a given subject from different points of view. PLA involves the designing of problems by students. The designing of problems by students can improve their grasp on the subject and can begin to focus their attention on the assessment of knowledge on the subject. The input of students can also help the instructor or teacher improve the course materials. The progress of the PLA process through problem design, solution design, solution evaluation and dispute arbitration can facilitate a thorough internalization or absorption of the given subjects by the students. The reading of other students' work can facilitate a broader understanding of the given subjects. 
Constructivist theories of teaching and learning raise the following interesting question: 'does teaching involve the transmission of knowledge or the facilitation of learning?' This question leads to a further question, 'who is a teacher?' In the authors' view a teacher is a person who possesses expert knowledge on the subject he/she is teaching by virtue of his/her academic qualifications. One can safely assert that the teacher possesses more knowledge about the subject he/she is teaching than the average student. This entails that at some level teaching must involve transmission of expert knowledge from the teacher to the student. However, what the constructivist literature on teaching and learning has to add to this is that learning is an active experience. One can agree with the constructivist literature on the point that the learning experience is greatly enhanced when the student is an active participant in the learning the process. It is here that the teacher's role as a facilitator of learning becomes important. The teacher can play a valuable role in facilitating active learning by students. Therefore, in the author's view the answer to the first question is that teaching involves both the transmission of knowledge and the facilitation of learning.

Since one of the authors has been trained in the social sciences another important question that comes to mind is 'what is the relevance of the constructivist approach to teaching and learning in the social sciences?' One of the authors has been trained in the social science discipline of International Relations (IR). Any academic discipline to be worthy of its status must have theories of its own. IR theory can be regarded as a branch of Social Science theory. Theory in the Social Sciences is essentially contested. This means that in IR, as in the other Social Sciences, there is more than one theory. One of the most important questions theories of International Relations try to answer is the following: "why do States go to war with other States?" (Brown and Ainley 2005). The three major theoretical approaches and paradigms in the discipline of IR are the following: Liberalism, Realism and Marxism. On the causes of war Liberalism, Realism and Marxism offer different explanations. According to Liberalism undemocratic states are more likely to go to war. Realists point to the anarchic nature of the international system as a cause of war. For Marxism imperialist states will resort to war in their search for resources, markets and investment opportunities. Thus, there is theoretical plurality in the discipline of IR. The constructivist approach to teaching and learning has much to offer to those engaged in teaching IR theory. Instead of inculcating students with just one of the three above mentioned theoretical explanations of war the constructivist approach would direct a teacher of IR theory not only to get the students to appreciate that there are different explanations on the causes of war but also to help the students understand merits and demerits of each explanation from different rational points of view. The constructivist approach would also direct the teacher under these conditions of theoretical plurality to encourage the students to bring their own ideas on the causes of war to the learning experience. The theoretical plurality in the discipline of IR provides the scope for students to generate their own explanations on the causes of war through some combination of the three different positions on the causes of war mentioned above or perhaps even by going beyond them. All of this would generate an intellectually rich participatory learning experience. Thus, the constructivist approach to teaching and learning with its emphasis on the ideas held by the students themselves and active learning is particularly suitable for a social science discipline such as IR with a plurality of theories.

The constructivist approach emphasizes that the active construction of knowledge by the learner is socially and culturally rooted. This emphasis raises an interesting dilemma for the teacher, which is, how seriously should the teacher take the socially and culturally rootedness of the learner's construction of knowledge? A traditionalist might argue that the student's social and cultural preconceptions are essentially subjective and should be left out of the classroom and that the student should engage in the learning experience on a purely rational and objective basis. But the constructivist approach highlights the subjective nature of the construction of knowledge and this claim is particularly relevant for the social sciences where essentially the student is studying the actions and interactions of human beings in areas such as politics, economics, society and culture. In the social sciences human beings are essentially studying their own actions and interactions and there is something inherently subjective about such an exercise. However, this is not to deny the importance of objectivity and the capacity for abstract thought in academic endeavor even about our own actions and interactions. For a teacher in the social sciences the best way to resolve the dilemma raised by the constructivist emphasis on the subjective and socially and culturally rootedness of the construction of knowledge by the learner is to encourage the learner to the reflect objectively and rationally on his/her subjectivity and the social and cultural roots of his/her preconceptions and to channel them into a productive learning experience. If properly channeled and harnessed in a rational and objective manner, the social and cultural diversity that student's bring to the classroom can be used to produce an extremely productive learning experience. This paper will assess the validity of the claims of constructivist teaching/learning theory through a survey of undergraduate students.

The final point the author would like to reflect on in this introductory section is the insistence of the proponents of PLA such as Jia Shen on student participation in assessment and evaluation (Shen, Wu et al. 2004). The positive 
aspects of PLA in the author's view are its encouragement of a collaborative and interactive learning experience and its attempt to get students to actively participate in the learning experience in a systematic manner. The PLA proponents support student participation in assessment and evaluation on the grounds that it will enhance the student's capacity for analytical thought in relation to the subject being taught. However, in this authors' view it would be better to encourage the student's capacity for analytical thought through other elements of PLA such as designing problems and solving problems. This is because an important quality of the assessor or the evaluator must be impartiality and when it comes to assessment, evaluation and grading the student is an interested party. That is to say, quite obviously, the students have a vested interest in how assignments are assessed/ evaluated and the grade he/she is going to obtain. Therefore this authors' position is that while there are many positive aspects to PLA, assessment, evaluation and grading is best left in the teacher's hands.

This paper will first survey some literature on teaching methods, second it will elaborate on the research design of this project, third it will present and analyze the data gathered from a survey of 41 undergraduate students at General Sir John Kotelawala Defence University (KDU) in Sri Lanka,and finally it will discuss the results of the survey to assess the validity of constructivist teaching/learning theory and the popularity and utility of participatory teaching methods.

\section{Teaching Methods: A Survey of Literature}

A document titled 'Participatory Teaching and Learning: A Guide to Methods and Techniques' prepared by the Malawi Institute of Education gives a comprehensive overview of different teaching methods (Education 2004). Some of the different teaching methods identified by this document are: 1) the lecture; 2) question and answer; 3 ) buzz groups; 4) discussion; 5) brainstorming; 6) role play; 7) case study; 8) debate; and 9) field visits/educational visits.

The lecture consists of trying to impart learning to the students by transmitting knowledge through the medium of speech. In the contemporary era PowerPoint presentations are utilized to provide a visual aid to this process. According to the Malawi Institute of Education the advantages of the lecture method are: 1) it is useful when introducing new subject matter or when presenting summaries or overviews to the students; 2) it is useful when used together with other participatory techniques; 3) it can be used for teaching groups of any size; and 4) it helps the teacher to cover a lot of content in a short space of time (Education 2004). According to the Malawi Institute of Education (2004) the disadvantages of the lecture method are: 1) it is usually presented as a monologue and does not take into account the individual needs, feelings or interests of students and it does not encourage feedback from the students; 2) it can lead to boredom among the students; 3 ) usually it does not give the students a chance to express their feelings and attitudes and therefore it makes it difficult to assess whether learning has taken place and to what extent; 4) the quality of learning through lectures can be poor, superficial and temporary; and 5) the teacher has to spend a lot of time preparing notes and in today's world PowerPoint presentations which may or may not be learnt by the students. The Malawi Institute of Education suggests the following measures for making the lecture method more effective: 1) varying the atmosphere of the lecture by using interest-arousing arousing aids such as pictures and diagrams; 2) organizing the presentation well so that the students can follow the lesson; 3 ) varying the stress of voice when lecturing to indicate essential points; 4) using transition words, phrases, sentences or statements to make the students follow what the teacher is saying and to make them realize that one point is finished and next point is beginning; and 5) asking questions during the lecture and creating deliberate opportunities for the students to ask their own questions and express their own ideas (Education 2004).

Malawi Institute of Education also discusses the question and answer method (Education 2004). This method consists of the teacher asking students questions. In employing this method, the teacher must be careful not to discourage students who give weak answers. That is to say the teacher must give a positive response even to weak answers so as to encourage the student to continue his/her participation in the learning process. The teacher should ask broad questions to encourage students to express their views. The question an answer method can help the teachers to assess the student's knowledge and how successful a lecture has been in imparting knowledge to the students. In order to aid assessment the Malawi Institute of Education suggests that the teacher ask higher order questions which require the students to "apply, synthesize and evaluate knowledge or information"(Education 2004). According to the Malawi Institute of Education the purpose of questions during different stages of the lesson can vary. A lesson can be divided into the following stages: introductory phase, development phase and conclusion phase. During the introductory phase the purpose of questions can be the following: 1) find out what students already know; 2) stimulate students' interest in the lesson; and 3) arouse the inquisitive mind of the student. During the 
development or the middle part of the lesson the purpose of questions can be the following: 1) check if students are following the discussion; 2) clarify any misconceptions that may develop as the lesson proceeds; and 3) encourage students to contribute to the knowledge being presented. During the conclusion phase of the lesson the purpose of questions can be the following: 1) evaluate the achievement of planned objectives; and 2) find out if any misconceptions still exist. The Malawi Institute of Education suggests the following as characteristics of goods questions: stimulation of thought; shortness, simplicity and clarity; encouragement of students to express themselves; relevance to the content of the lesson; and appropriateness to the student's ability. The following are some of the measures suggested by the Malawi Institute of Education for the making the question and answer method more effective (Education 2004):

1. Questions should be written in advance on a piece of paper in order to make it easier for the teacher;

2. After posing the question the teacher should wait for about five seconds and then ask a student to answer;

3. The teacher should probe the student's answers through why, what and how questions to provoke thought and induce a longer explanation;

4. The teacher should ask questions of varied levels of difficulty;

5. The teacher should discourage chorus answers;

6. The teacher should ask questions that are within the student's ability; and

7. The teacher should not repeat or rephrase questions unless requested to do so by the students.

A third teaching method identified by the Malawi Institute of Education (2004) is the Buzz Group. This method essentially consists of breaking up the class into groups and asking them to discuss a specific issue drawn from the lecture. The name 'Buzz Group' comes from the fact that when this method is employed the classroom will 'buzz' with the noise generated by the student discussion groups. After a given period of time one student from each group must give a summary of his/her group's discussion to the whole class. During these group discussions students will be able to "exchange ideas drawn from their collective abilities, knowledge and experiences". The Malawi Institute of Education gives the following guidelines for the effective use of the Buzz Group method(Education 2004):

1. Explain the task or issue to be discussed before the class breaks up into groups;

2. Organize the students into mixed ability groups or same ability groups as needed;

3. The teacher should supervise the group discussions in order to encourage students in difficulty;

4. The teacher should appoint a leader for each group and if the Buzz Group method is employed more than once during a course the group leadership should be rotated so that a different student leads the group each time;

5. The teacher can give different but related tasks to each group to motivate and give each group a special responsibility;

6. If the teacher gives the same task to all groups organize feedback in such a way that one group presents their ideas, with other groups only contributing new ideas or let one group report only one point at a time until all groups have contributed;

7. The teacher must manage the feedback from the groups in a concise manner; and

8. Both the teacher and the students must be time conscious.

A fourth teaching method identified by the Malawi Institute of Education is 'discussion'. The discussion method(Education 2004),

Permits open interaction between student and student as well as between teacher and student. It involves free flowing conversation, giving students an opportunity to express their opinions and ideas, hear those of their peers and the teacher. The teacher does not take the leadership role. He/she rather participates as a member of the groups. And everyone adheres to the guidelines for specified acceptable discussion behavior. If properly planned and structured, the discussion method involves pupils in higher order cognitive skills such as analysis, synthesis and evaluation(Education 2004).

According to the Malawi Institute of Education the following are some of the occasions on which the discussion method can be employed: when checking what has been learnt after a field or an educational trip; when exploring the opinions, knowledge and experiences of pupils; and when giving students practice in forming, expressing and evaluating opinions. It also gives the following guidelines for employing the discussion method(Education 2004): 
1. The topic chosen for discussion should be interesting and relative to the students' level of learning, which can ensure maximum student participation during the discussion;

2. The discussion should be structured by means of a series of questions;

3. The teacher should clarify important terms before the discussion in order to help students understand better the topic under discussion;

4. The teacher must ensure that only one student speaks at a time during the discussion;

5. The teacher must follow up on interesting points raised by the students in order to assist them to understand the major points of the topic under discussion;

6. The teacher must ensure that the discussion adheres to its objectives and takes place within the given amount of time; and

7. The teacher must write down the main points of the discussion on the white board.

A fifth teaching method identified by the Malawi Institute of Education is 'brainstorming'. Brainstorming can get the students involved in generating ideas on a given topic. Brainstorming can be done with the class as a whole or in small groups. When brainstorming it is important not to evaluate ideas at first, rather all ideas must be recorded on the white board or a piece of paper in a concise manner. The evaluation of ideas and relating the different ideas to each other must be done after all ideas are recorded. If brainstorming is done in small groups the better students can be allowed to take the lead. According to the Malawi Institute of Education (2004) brainstorming is effective for the following: sensitive and controversial issues that need to be explored; encouraging students who are quite and hesitant to enter into discussions; and generating a large number of ideas in the shortest possible time. The advantages of brainstorming identified by the Malawi Institute of Education are as follows: 1) gives students the chance to think through issues; 2) promotes respect for each other's ideas among the students; 3) it is a quick and effective way to generate ideas from the students; 4) it encourages all students to express their ideas freely because the ideas are not evaluated immediately; 5) it is a useful way of determining the student's knowledge about a given topic prior to getting into it; and 6) if brainstorming is done in groups the ideas generated are owned collectively by that group of students. The disadvantages of brainstorming identified by the Malawi Institute of Education are as follows: 1) it is difficult to ensure that all students contribute particularly if the class is large; and 2) after brainstorming reorganizing the ideas generated can be time consuming(Education 2004).

A sixth teaching method identified by the Malawi Institute of Education is 'role play'. The role play method can be used to simulate a real life situation pertaining to the subject or topic being taught. The use of the role play method can give the students an opportunity to use their creativity in the process of learning. The role play method can be employed using groups of students. Each group of students can act out a real life situation pertaining to the subject or topic being taught with other students and the teacher watching. The students can comment on each other's role plays. The role play can be a practical learning experience(Education 2004).

The Malawi Institute of Education gives the following as guidelines for role play:

1. The teacher must give a description of the different roles to be played and the situation to be acted out to the students;

2. The teacher must ask for volunteers or allocate different students to act out the different roles and the situation;

3. The teacher can inform the student actors that they can be creative in acting out the roles allotted to them;

4. The teacher must give the students time to prepare the role play and about five-ten minutes can be given to act out the role play;

5. The role play must be discussed after the performance; and

6. The teacher must ensure that the students are aware that they are merely acting out the given roles and situation.

A seventh teaching method identified by the Malawi Institute of Education (2004) is the 'case study'. The case study method involves an in-depth description and analysis of a specific incident or event relevant to the subject or topic being taught. The case study method can be implemented through group study. One of the advantages of the case study method mentioned by the Malawi Institute of Education is that it is useful in developing analytical, problem solving and decision making skills (Education 2004).

An eighth teaching method identified by the Malawi Institute of Education is 'debate'. A classroom debate will involve two teams which one team arguing for the 'yes' side of an issue and the other team arguing for the 'no' side 
of the issue. Each team should be given time to prepare for the debate and each team should have two or three speakers. The Malawi Institute of Education (2004) gives the following as guidelines for conducting classroom debates: 1) there should be chairperson to conduct the debate; 2) the chairperson must introduce the speakers and keep order; 3 ) there should be a time limit of about five minutes for each speaker; and 4) the speakers should stand in front of the main group and articulate their arguments(Education 2004).

A ninth teaching method identified by the Malawi Institute of Education is the 'field/educational visit'. There are two types of activity involved here, one is the field visit and the other is the educational visit. According to the Malawi Institute of Education(Education 2004),

Field trips are lessons conducted outside the classroom with the aim of giving pupils first hand information and experiences on subject matter under discussion. The trip is part of ongoing study and teachers' should prepare in advance activities for pupils to do at the site.

On the other hand, educational visits are outings for the purpose of strengthening what is learnt in the classroom. The difference between the field visit and the educational visit is that in the field visit the teacher has to prepare activities to be done at the field site while in the educational visit the teacher does not play a major formal role at the visited site. The following are some of advantages of the field/educational visit listed by the Malawi Institute of Education (2004): 1) students gain knowledge, skills and attitudes by observing; 2) students can relate classroom ideas to the real world; 3) provides students with a chance to engage in practical work related to what they have learned; and 4) provides students with variety in learning. The following are some of disadvantages of the field/educational visit listed by the Malawi Institute of Education (2004): 1) time consuming; 2) requires a lot of arrangement and organization; 3) can require parental consent; 4) prone to eventualities; and 5) visits may incur monetary costs with regard to transportation and meals.

The above surveyed document produced by the Malawi Institute of Education provides an extremely helpful and practical guide to teaching methods. This is why it has merited so much attention and space in this survey section. Ultimately this document recommends that in a given lesson the teacher should employ at least three teaching methods to enhance the learning experience of students. This paper will subject the teaching methods elaborated on by the Malawi Institute of Education document to an empirical evaluation. This will be done through the means of a survey of undergraduate student views on the above elaborated on teaching methods. The survey conducted among undergraduate students at KDU, Sri Lanka will assess the popularity of the teaching methods identified by the Malawi Institute of Educations and the utility of two participatory teaching methods, the 'question and answer' method and the 'buzz group/group discussion' method, employed in the classroom by one of the authors.

B.D. Bhatt (2002) contains an interesting chapter on 'Uses of Classroom Discussion'. According to Bhatt (Bhatt 2002),

A useful classroom discussion...consists of student comments separated by frequent probes and clarifications by the teacher that facilitate involvement and development of thinking by the whole group. Dynamic lecturers captivate a class by the virtuosity of their individual performances. Master discussion leaders accomplish the same end by skillful guidance of the group's collective thinking processes.

In Bhatt's (2002) view the success of classroom discussion depends a great deal on the active involvement of the students. The ability of the teacher to get the students involved in the discussion depends in turn on the teacher's inter-personal skills (Bhatt 2002). That is to say it depends on the connection the teacher establishes with the students. In order for classroom discussions to be effective the teacher must understand the students as much as the students understand the teacher. If a teacher is familiar with the ideas of his/her students it would be easier to generate stimulating classroom discussions. The discussion method is an important way of generating active participation by students in the learning process.

Finally, in this survey section on teaching methods it important not to neglect the utilization of the latest technological developments to enhance the learning experience. The Report to the European Commission on New Modes of Learning and Teaching in Higher Education published in 2014 provides an insight into how this can be done. According to the European Union(Union 2014),

Students are unique and so is the way they learn. Therefore, the teaching tools used in universities and colleges should cater for individual ways of learning, with the student at the centre. Some of our students will learn better and faster with the help of interactive media that incorporate images, graphics, video and audio elements. Others will prefer static text and numbers in different measures. Technology in the classroom can combine all of these for a personalized learning experience for each student, based on each student's strengths. 
Essentially the European Union (Union 2014) report points out that the latest developments in communication technology can be utilized to increase the level of interaction between the teacher and the students as well as between the students themselves. Such increased interaction can enable teachers to find out the learning levels of individual students and to cater to their individual needs. In addition, online interaction among students can facilitate collaborative learning. Online platforms and software packages can be utilized for these purposes.

\section{Research Design}

In this study, we have examined General Sir John Kotelawala Defence University's (KDU's) cadet and civilian students' response to constructivist learning theory and participatory teaching methods, especially concepts and knowledge on the learning platform in the Defence university system. This topic was judged to be extremely important to have a conceptual understanding of what is teaching methods and to find out in detail knowledge on current trends in using appropriate teaching methods in a state Defence university. The study design in this study is presented in the Figure 1. Approval for the study was obtained from the Staff Development Center. Target population of this study represents 11 cadet students following the Strategic and Defence Studies (SDS) undergraduate course and 30 civilian students following an International Relations (IR) undergraduate course. All students were given a questionnaire related to constructivist learning theory and participatory teaching methods. Forty-one students, which participated in the study and gave their consent, were included in the study. The purpose of the study was explained to the students at the beginning of collecting data. The cadet students who consented to participate in the study were individually tagged and given them a tag. $(n=41)$.

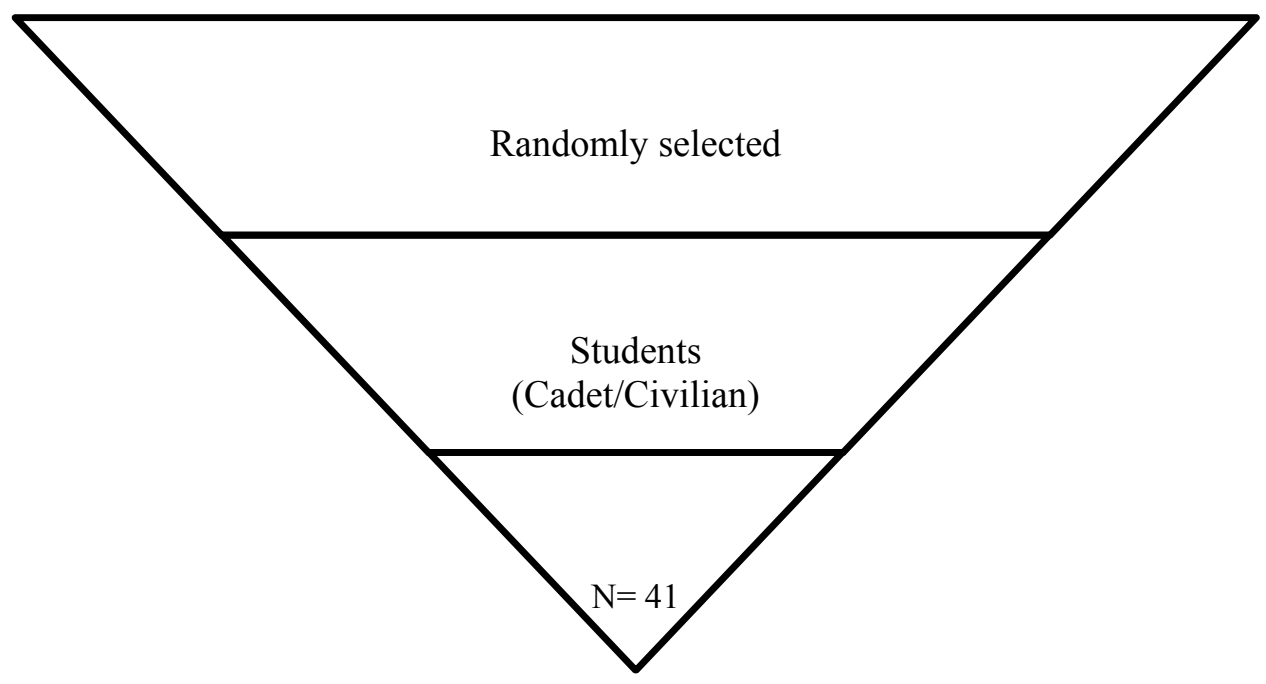

Figure 1. Study Design

\section{Research Context and Participants}

Forty-one cadet and civilian students took part in this study. All cadet students were employed at the university as cadet officers enrolled as students. The civilian students were second year LLB students. KDU's student population is a socially and economically diverse community in Western Province of the country in the one and only Defence University in Sri Lanka. The students had the background knowledge of constructivist learning theory and participatory teaching methods.

\section{Administration of Questionnaire among Cadet and Civilian Students}

The questionnaire was administered among each of the forty-one respective cadets and civilian students of the sample population at the university; with respect to constructivist learning theory and participatory teaching methods within a period of two semesters they have to answer the entire questionnaire. Care was taken to avoid exchanging the students' information or ideas. 


\section{Data Presentation and Analysis}

To analyze the questions, we compared informal reasoning displayed by individuals representing high and low level of understanding of teaching methods. The validity of the translation was independently assessed by two observers competent in the English language. We analyzed our data as a balanced figure in a percentage of application. For statistical analysis, we transformed all our data using the basic statistical analysis package

1. Do you think learning is a passive experience?

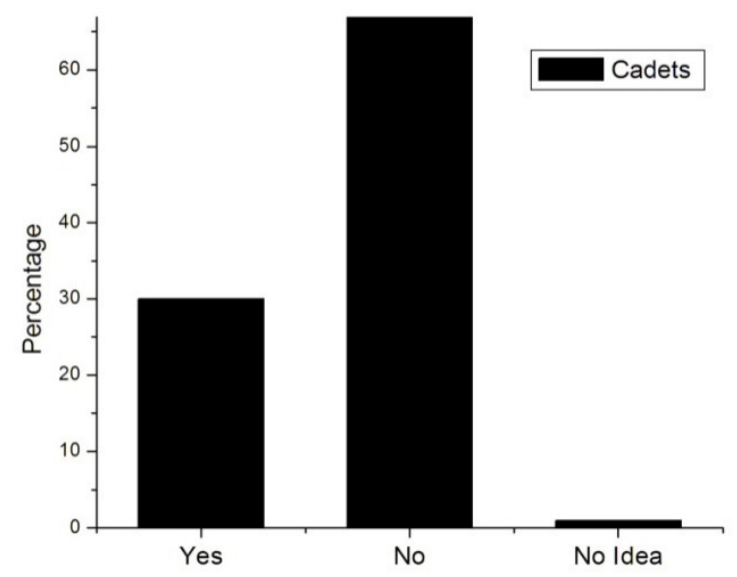

Figure 2. Outcome of Passive Learning

Yes: approximately $12=30 \%$

No: approximately $28=68 \%$

No Answer, approximately $\quad 1=2 \%$

For the first question 12 students have answered 'yes', 28 students have answered 'no', that is $30 \%$ have answered 'yes', 68\% have answered 'no'.

2. Do you think learning is an active experience?

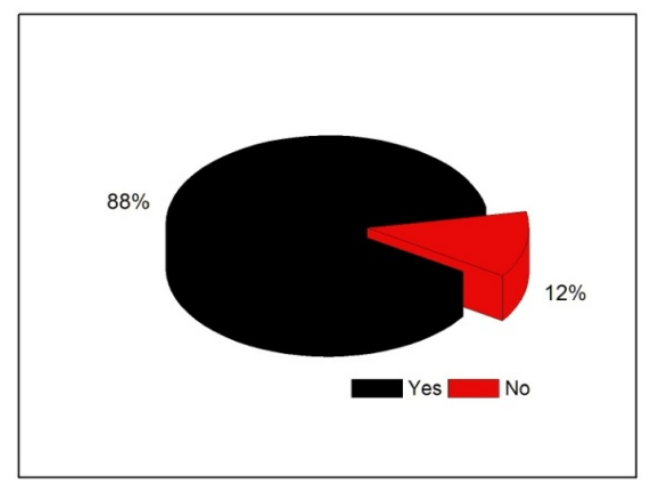

Figure 3. Outcome Experience on Active Learning

Yes: approximately $=36=87 \%$

No:, approximately $=5=13 \%$

For the second question 36 students answered 'yes', 5 students answered 'no', that is $87 \%$ answered 'yes', $13 \%$ answered 'no'.

3. Do you reflect on your own ideas when you are listening to a lecture? 


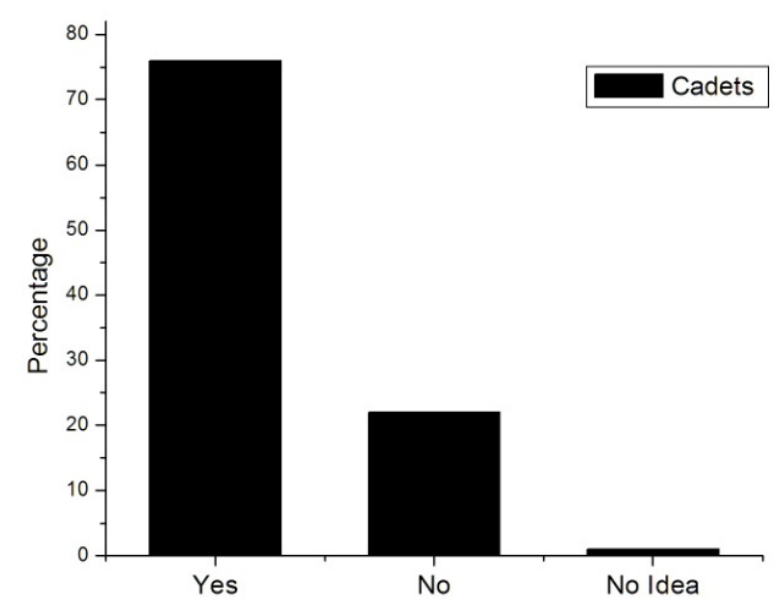

Figure 4. Behavioral Change after Listen to a Lecture

On the third question 31 students answered 'yes', 9 student answered 'no', that is $75 \%$ answered 'yes', $23 \%$ answered 'no' and $2 \%$ no answer

4. Do you reflect on your subjective social and cultural preconceptions when you are listening to a lecture?

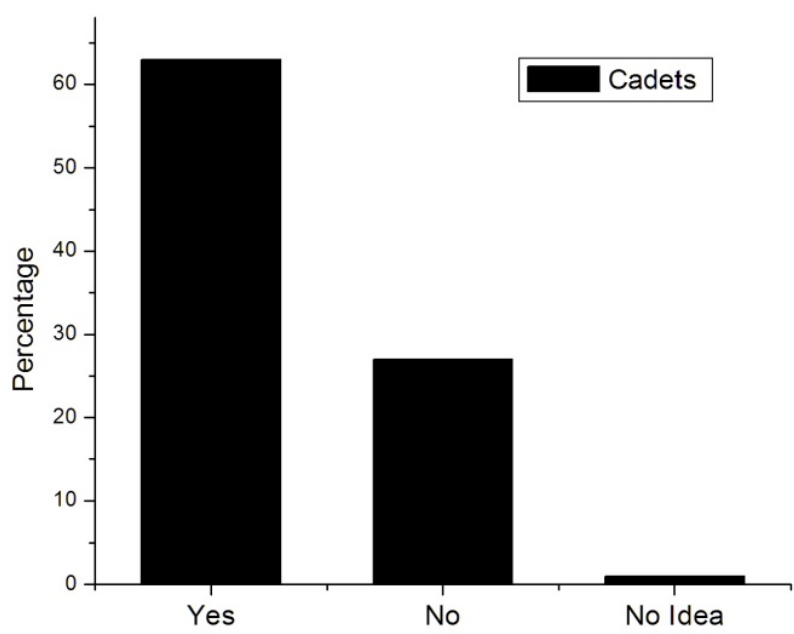

Figure 5. Social and Cultural Change after Listen to a Lecture

Yes: approximately $63 \%, 26$

No: approximately $27 \%, 11$

No Answer: approximately $10 \%, 4$

On the fourth question 26 students answered 'yes', 11 students answered 'no', that is 63\% answered 'yes', $27 \%$ answered 'no' and no answer $10 \%$

5. Would you like to actively participate in the learning experience 


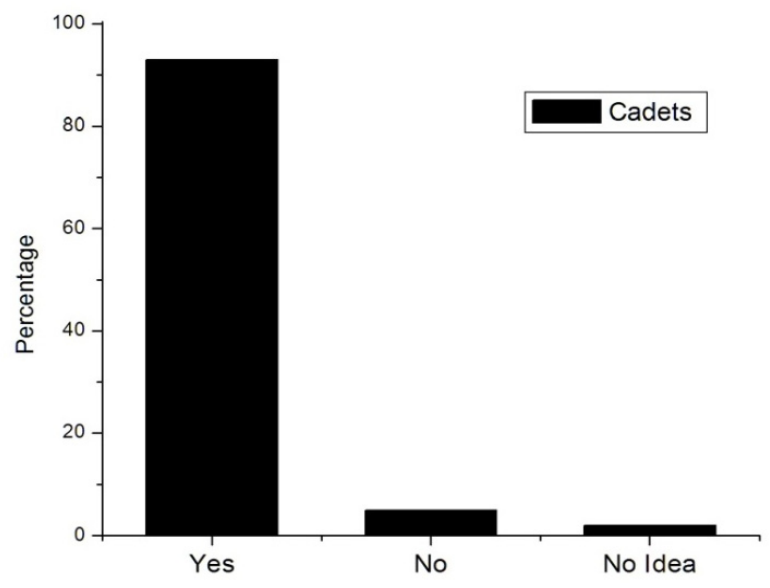

Figure 6. Results of Learning Experience in Active Learning

On the fifth question 38 students answered 'yes', 2 students answered 'no', that is a 93\% answered 'yes' and 5\% answered 'no' and no answer approximately $2 \%$

Yes: approximately $93 \%, 38$

No: approximately $5 \%, 2$

No Answer: approximately $2 \%, 1$

Table 1. Responses for the Questions

\begin{tabular}{lccc}
\hline Item & Yes & No & No Answer \\
\hline Do you think 'the lecture' is a good teaching method? & $57 \%$ & $37 \%$ & $07 \%$ \\
Do you think 'question and answer' is a good teaching method? & $77 \%$ & $20 \%$ & $03 \%$ \\
Did the use of the 'question and answer' method improve your learning? & $83 \%$ & $13 \%$ & $03 \%$ \\
Do you think 'group discussion' is a good teaching method? & $63 \%$ & $33 \%$ & $03 \%$ \\
Did the use of the 'group discussion' method improve your learning? & $73 \%$ & $23 \%$ & $03 \%$ \\
Do you think 'discussion' is a good teaching method? & $93 \%$ & $03 \%$ & $03 \%$ \\
Do you think 'brainstorming' is a good teaching method? & $67 \%$ & $27 \%$ & $07 \%$ \\
Do you think 'role play' is a good teaching method? & $57 \%$ & $37 \%$ & $07 \%$ \\
Do you think 'case study' is a good teaching method? & $53 \%$ & $40 \%$ & $07 \%$ \\
Do you think 'debate' is a good teaching method? & $47 \%$ & $47 \%$ & $07 \%$ \\
Do you think 'educational visits' is a good teaching method? & $93 \%$ & $00 \%$ & $07 \%$ \\
\hline
\end{tabular}

\section{Discussion}

This paper has explored constructivist teaching and learning theory. In this section which will discuss the results the premises of the constructivist teaching and learning theory as well as its prescription will be assessed with the use of the survey results. The first premise of constructivist theory that must be highlighted is that learning is an active experience. For the first question of the survey questionnaire 'do you think learning is a passive experience?', 12 students have answered 'yes', 28 students have answered 'no', that is $30 \%$ have answered 'yes', $68 \%$ have answered 'no'. For the second question of the survey questionnaire 'do you think learning is an active experience?', 36 students answered 'yes', 5 students answered 'no', that is $87 \%$ answered 'yes', $13 \%$ answered 'no'. Thus the survey results tend to support constructivist premise that learning is an active experience. Constructivist theory also holds that the ideas students hold about the subject and topic being taught will form a part of their learning experience. For the third question of the survey questionnaire 'do you reflect on your own ideas when you are listening to a lecture?', 31 students answered 'yes', 9 students answered 'no', that is $75 \%$ answered 'yes', $23 \%$ answered 'no'. Thus the 
survey results give solid support for this second constructivist premise that ideas held by students are an important part of the learning experience. A third premise advanced by the constructivist theory is that learning is socially and culturally rooted. For the fourth question of survey questionnaire 'do you reflect on your subjective social and cultural preconceptions when you are listening to a lecture?', 26 students answered 'yes', 11 students answered 'no', that is $63 \%$ answered 'yes', $27 \%$ answered 'no'. Thus, the survey results also support the third constructivist premise. Constructivist theory prescribes a participatory approach to teaching and learning. For the fifth question of the survey questionnaire 'would you like to actively participate in the learning experience?', 38 students answered 'yes', 2 students answered 'no', that is $93 \%$ answered 'yes', $5 \%$ answered 'no'. Thus, the survey results give overwhelming support for constructivist recommendation of a participatory approach to teaching and learning. Therefore, in general the survey results offer firm support for constructivist teaching and learning theory.

There have been many valuable applications of constructivism, particularly to science and math teaching (Driver and Oldham 1986; Cobb 1994) but there have been few attempts to provide a framework that would generalize beyond the contexts or topics for which they were designed. One needs to be careful about this as a prescriptive "constructive method" is contrary to the principles of constructivism. What is involved here is not a particular method but an attitude towards teaching which implies a focal awareness of the learner and the learner's world when compared with our study, each teacher has to tackle the principles and appropriate them within the context of his or her own teaching. But how is the teacher to move from a "focal awareness ... of the learner's world", and appropriating principles, to doing things differently? This is the familiar hiatus between espoused theory and theory-in-use.

This paper has elaborated on teaching methods both traditional and participatory. With regard to teaching methods it is the authors' view that the traditional teaching method of lecturing must be combined with participatory teaching methods such as 'question and answer' and 'group discussion' to generate an active learning experience. At this point in the discussion of results the student responses to different teaching methods will be examined in order to gauge the level of support among students for different teaching methods. The participatory methods of 'question and answer' and 'group discussion' were utilized by one of the authors with the survey sample of 41 students, consisting of 11 cadet students following the Strategic and Defence Studies (SDS) undergraduate course at KDU and 30 civilian students following one of the International Relations (IR) courses offered at KDU.

For the sixth question of the survey questionnaire 'do you think 'the lecture' is a good teaching method?',57\% answered 'yes', 37\% answered 'no'. This indicates that there is support among a simple majority of the surveyed students for the traditional method of 'the lecture'. For the seventh question of the survey questionnaire 'do you think 'question and answer' is a good teaching method?', 77\% answered 'yes', 20\% answered 'no'. This indicates that there is substantial support among the surveyed students for the participatory 'question and answer' teaching method. For the eighth question of the survey questionnaire 'did the use of the 'question and answer' method improve your learning?', $83 \%$ answered 'yes', $13 \%$ answered 'no'. The response to question eight is firm evidence that the use of the participatory teaching method of 'question and answer' had a positive impact on student learning. For the ninth question of the survey questionnaire 'do you think 'group discussion' is a good teaching method?',63\% answered 'yes', 33\% answered 'no'. This indicates that there is substantial support among the surveyed students for the participatory teaching method of 'group discussion'. For the tenth question of the survey questionnaire 'did the use of the 'group discussion' method improve your learning?',73\% answered 'yes', $23 \%$ answered 'no'. The response to question ten indicates that there is firm evidence that the use of the participatory teaching method of 'group discussion' had a positive impact on student learning. For the eleventh question of the survey questionnaire 'do you think 'discussion' is a good teaching method?', 93\% answered 'yes', 3\% answered 'no'. This indicates that there is overwhelming support among the surveyed students for the participatory teaching method of 'discussion'. For the twelfth question of the survey questionnaire 'do you think 'brainstorming' is a good teaching method?', 67\% answered 'yes', 27\% answered 'no'. This indicates that there is solid support among the surveyed students for the participatory teaching method of 'brainstorming'. For the thirteenth question of the survey questionnaire 'do you think 'role play' is a good teaching method?', 57\% answered 'yes', $37 \%$ answered 'no'. This indicates that there is some support among a simple majority of the surveyed students for the participatory teaching method of 'role play'. For the fourteenth question of the survey questionnaire 'do you think 'case study' is a good teaching method?',53\% answered 'yes', 40\% answered 'no'. This indicates that there is support among a simple majority of the surveyed students for the participatory teaching method of 'case study'. For the fifteenth question of the survey questionnaire 'do you think 'debate' is a good teaching method?', $47 \%$ answered 'yes', $47 \%$ answered 'no'. This indicates that the students were evenly divided in their support and lack of support for the participatory teaching method of 'debate'. Thus 'debate' is the only participatory teaching method for which the survey results do not offer even a simple majority in support. For the sixteenth question of the survey questionnaire 'do you think 'educational visits' is a good 
teaching method?',93\% answered 'yes', $0 \%$ answered 'no'. This indicates that there is overwhelming support among the surveyed students for the participatory teaching method of 'educational visits'.

With regard to teaching methods, in general, the results of the survey indicate that while a simple majority of the students support the traditional teaching method of 'the lecture', they also give a substantial degree of support to the use of participatory methods of teaching. This tends to support the authors' view that it is best to use the traditional teaching method of 'the lecture' in combination with participatory teaching methods such as 'question and answer' and 'group discussion'. From among the participatory teaching methods the highest level of support by the surveyed students was given to 'discussion', 'educational visits' and 'question and answer', while others such as 'group discussion' and 'brainstorming' also received a fairly high degree of support. Overall the survey results offer firm support for the use of participatory teaching methods to improve student learning.

\section{Conclusion}

This paper has focused on constructivist teaching/learning theory and participatory teaching methods. It has subjected some of the claims of constructivist teaching/learning theory to empirical evaluation. The claims of constructivist teaching/learning theory that this paper has singled out are the following: 1) learning is an active experience; 2) the ideas students hold about the subject and topic being taught will form a part of their learning experience; and 3) learning is socially and culturally rooted. These claims were subjected to empirical evaluation through a survey of 41 undergraduate students at KDU, Sri Lanka. The student responses to the survey comfortably validate the three claims of constructivist teaching/learning theory singled out above. Constructivist teaching/learning theory also prescribes a participatory approach to teaching and learning. The survey conducted offered strong support to this prescription. The survey conducted also revealed that participatory teaching methods have a high level of popularity among undergraduate students. In addition, the survey established the utility of the participatory teaching methods of 'question and answer' and 'group discussion' in improving the learning experience. Thus, overall the research presented in this paper support constructivist teaching/learning theory and participatory teaching methods.

However, this does not mean that this paper does not value the traditional teaching method of the 'lecture' and the traditional learning method 'listening'. It must be emphasized that a simple majority of the surveyed students did think that the 'lecture' was a good teaching method. Thus, this paper advocates combining the traditional teaching method of the 'lecture' with participatory teaching methods to improve the learning experience. While constructivists emphasize subjectivity the value of objectivity in the classroom should not be demeaned. Rather objectivity and subjectivity must be rationally and judiciously combined in the classroom to generate a productive learning experience.

\section{Conflict of Interests}

The authors declare that there is no conflict of interests regarding the publication of this paper.

\section{References}

Bhatt, B. D. (2002). Modern Methods of Teaching. New Delhi, Kanishka Publishers.

Brown, C., \& K. Ainley. (2005). Understanding International Relations. Basingstoke, Palgrave Macmillan Houndmills.

Cobb, P. (1994). Where is the mind? Constructivist and sociocultural perspectives on mathematical development. Educational Researcher, 23(7), 13-20. https://doi.org/10.3102/0013189X023007013

Driver, R., \& V. Oldham. (1986). A constructionist approach to curriculum development in science. Studies in Science Education, 13, 105-122. https://doi.org/10.1080/03057268608559933

Education, M. I. O. (2004). Participatory Teaching and Learning Theory: A Guide to Methods and Techniques. Malawi, Malawi Institute of Education.

Shen, J., \& D. Wu, et al. (2004). Participatory Learning Approach: A Research Agenda', Information Systems Department. New Jersey, College of Computing Sciences.

Sjoberg, S. (2007). Constructivism and Learning. In E. Baker, B. McGaw and P. Peterson, (eds.), International Encyclopedia of Education (3rd edition.). Oxford, Elsevier. 
Union, E. (2014). Report to the European Commission on New Modes of Learning and Teaching in Higher Education. Luxembourg, European Union.

VonGlaserfeld, E. (1989). Constructivism in Education. In T. Husen and T.N. Postlethwaite (eds.), The International Encyclopedia of Education, Supplement. Oxford/New York, Pergamon Press. 